\title{
A Rare Case of Double Belly Soleus Muscle
}

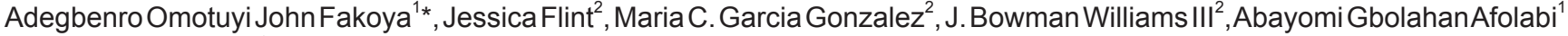 \\ Thomas McCracken ${ }^{1}$ \\ ${ }^{1}$ Department of Anatomical Sciences, University of Medicine and Health Sciences, Basseterre, St. Kitts and Nevis; ${ }^{2}$ Medical \\ Student, University of Medicine and Health Sciences, Basseterre, St. Kitts and Nevis
}

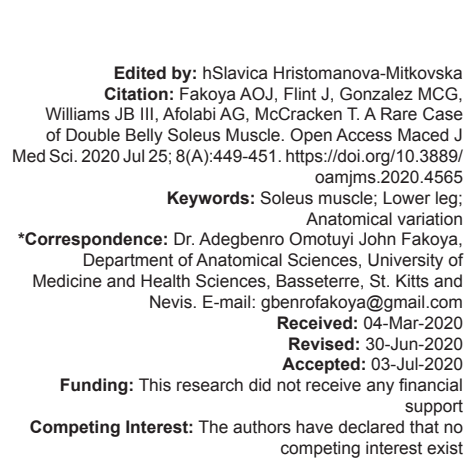

Introduction

The double belly soleus muscle is a rare anatomical anomaly that has been found in other articles to have both clinical and non-clinical relevance [1], [2]. The soleus muscle is located posteriorly in the lower aspect of the leg near the ankle region. The origin of this muscle arises at the fibula and the medial border of the tibial line. The insertion of this muscle could be in either two places, inserting into the Achilles tendon or the calcaneus medial, anterior and inferior part of the regular Achilles tendon insertion [3]. The soleus muscle is responsible for plantar flexion of the foot which is essential for walking, running, and balance when standing, thus rare abnormalities with this muscle can make it challenging to perform these actions [4].

The finding of the accessory soleus muscle is usually not noticed unless in surgery, or a biopsy is taken, but computed tomography (CT) and magnetic resonance imaging (MRI) machines have been getting better at capturing this anatomy variation [5]. There have been several reports of this anomaly causing some painful complications in patients as they walk or run [1], [5]. There have also been reports of this anomaly having shown no complications, estimated to occur in $0.7-5.6 \%$ of individuals with this accessory muscle [2]. In this study, we present a cadaver with an accessory soleus muscle with a showing the extra soleus belly.

\section{Case Report}

Lower limb anomaly was discovered in a 58-yearold female cadaver during an Anatomy Lab Dissection Class at the University of Medicine and Health Sciences, St. Kitts and Nevis. We identified an accessory soleus in both the right and left limbs. An accessory soleus muscle was identified in each limb after the skin and fat were removed in a manner that preserved underlying structures, lower limb muscles separated, and gastrocnemius muscle dissected in a way that the expected normal soleus muscle inserting into the calcaneus alone could be identified. In both instances, there was an abnormal belly with an incorrect insertion. The incorrect insertion was at the medial calcaneus (Figures 1 and 2).

\section{Discussion}

The soleus muscle is a plantar flexor of the ankle. It is found on the calf, immediately under the gastrocnemius muscle. It arises from the posterior aspect of the tibia bone and inserts with gastrocnemius aponeurosis into the calcaneus, forming the Achilles tendon. Having a double belly soleus muscle can mean to have an accessory soleus muscle. The accessory 


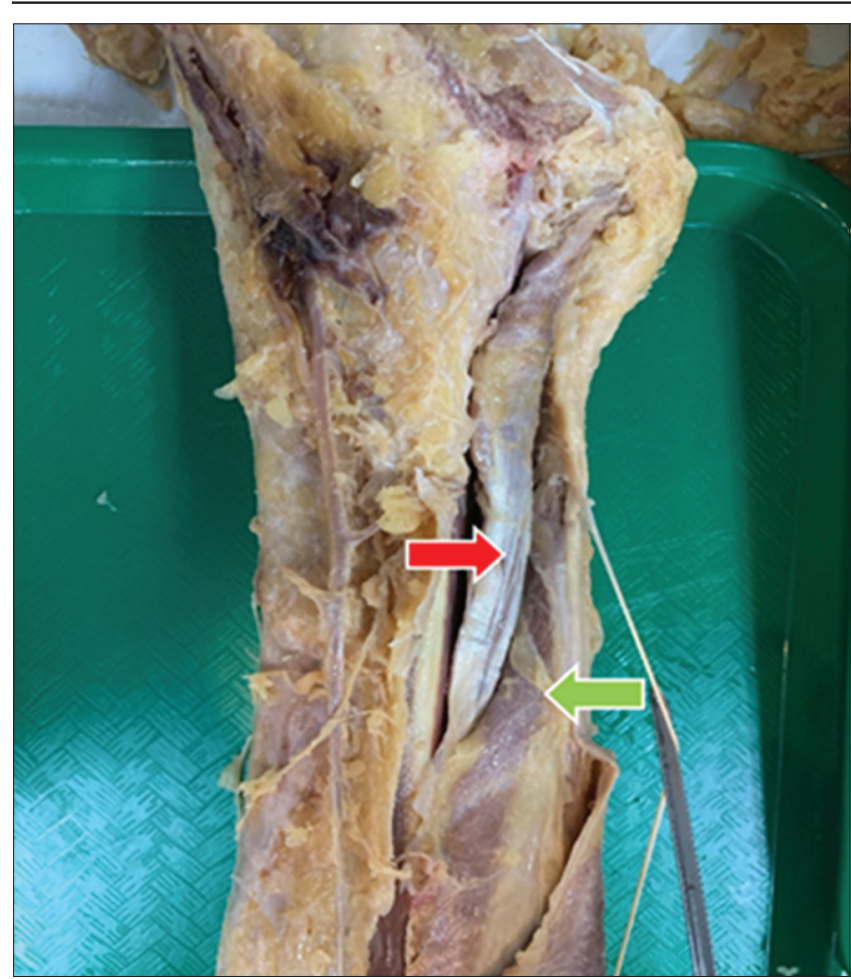

Figure 1: Double belly soleus right leg. Green arrow indicates normal soleus belly with calcaneus insertion and red arrow indicates abnormal or accessory soleus belly

soleus muscle can originate from one of two different areas, a part of the soleus and from the fibula and tibia. A soleus muscle could appear during embryological development due to early splitting [6]. It is possible for the abnormal belly and normal belly to have different nerve innervation and blood supply. An average age

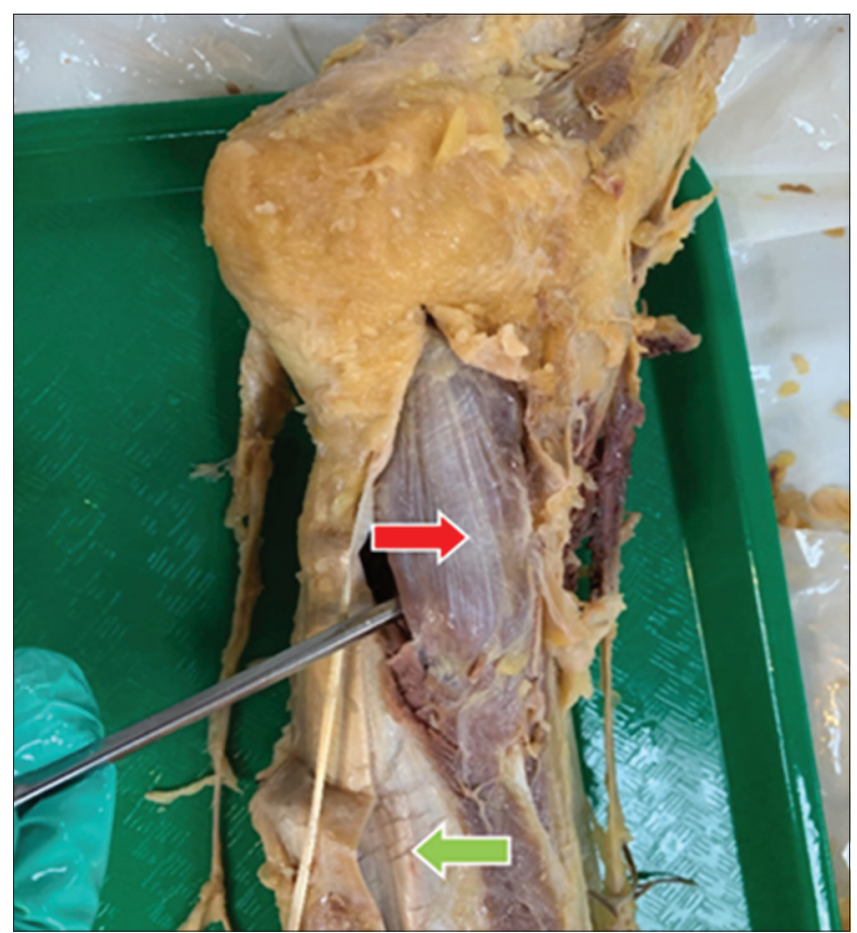

Figure 2: Double belly soleus right leg. Green arrow indicates normal soleus belly with calcaneus insertion and red arrow indicates abnormal or accessory soleus belly for having an accessory soleus muscle identified is 19 years [7]. It is plausible that around $10 \%$ of the population could possess an accessory soleus muscle [8]. Males are seen to have this anomaly more often than females. This anomaly is likely to be unilateral. When bilateral, one muscle is larger on one side [9]. Usually, a patient with this anomaly can present with pain, swelling, and equinus deformity. Intense activity or physical predisposes an individual with the condition to have negative symptoms, such as swelling or pain, with these symptoms absent when at rest [9]. In some cases, nonpainful swelling can be present at birth and patients can go years without medical attention [1]. If symptoms do occur, they normally do not start to cause problems until the second or third decade of life [2]. During those times, the swelling and pain increase with prolonged standing and walking [1]. An accessory soleus with intense action can cause a person to experience ankle pain. In addition, it is possible for a patient with an accessory soleus muscle to experience cramping pain while being active and tenderness in a particular location [10].

Table 1: Occurrence of accessory soleus muscle from previous studies

\begin{tabular}{llll}
\hline Study year & $\begin{array}{l}\text { Number of cadavers } \\
\text { with accessory soleus }\end{array}$ & $\begin{array}{l}\text { Number of } \\
\text { cadavers }\end{array}$ & $\begin{array}{l}\text { Percentages of cadavers } \\
\text { with accessory soleus }\end{array}$ \\
\hline 1864 & 2 & 50 & 4.0 \\
1867 & 2 & 36 & 5.5 \\
1869 & 3 & 158 & 1.9 \\
1871 & 1 & 138 & 0.7 \\
1873 & 2 & 160 & 1.3 \\
1943 & 1 & 100 & 1.0 \\
1993 & 2 & 47 & 4.3 \\
\hline
\end{tabular}

Table 1: This table depicts percentages of cadavers that had an accessory soleus for seven different studies. These studies took place from 1984 to 1993, each from a different year. These data help one better understand the frequency of an accessory soleus. The highest amount of cadavers with an accessory soleus identified in any of these studies was three. Each study consisted of 36-160 cadavers. One of the cadavers from the 1993 study had an accessory soleus on both sides. The sex and age were female 91 years old. This table was created based on a table located in the previous literature and was modified from its original form [10].

Table 2: State of Kager's triangle in accessory soleus muscle presentation

\begin{tabular}{llll}
\hline Patient & Sex & Age at diagnosis & Obliteration of Kager's triangle \\
\hline 1 & Male & 26 & None \\
2 & Male & 29 & Yes, left, and right \\
3 & Female & 23 & Yes, left, and right \\
4 & Male & 19 & Yes, left, and right \\
\hline
\end{tabular}

Table 2: The state of Kager's triangle is important when diagnosing accessory soleus muscles [11]. According to literature from 1993, four patients had bilateral accessory soleus muscles. Three out of the four patients had obliteration of Kager's triangle on both sides. One patient did not have obliteration of Kager's triangle on either side. Three of the patients were male and one was female. The oldest diagnosis age was 29 and the youngest was 19 years old. This table was created based on a table located in the previous literature and was modified from its original form [10]. 
To diagnose a patient with an accessory Soleus muscle, either an MRI, CT, or an Ultrasound must be performed. In spite of all these methods to diagnose an accessory muscle, it has been investigated that the MRI has the ability to differentiate the accessory muscle from soft-tissue neoplasm, which is suggested to be performed on patients suspected of having this anomaly [11]. To treat this anomaly a complete excision, fasciotomy and anti-inflammatory medication can relieve the patient's symptoms [3], [11].

\section{Conclusion}

The knowledge of variations of the soleus muscle can help the clinician to follow the appropriate treatment related to the patient's symptoms, especially when the diagnosis is unclear. MRI, CT, or ultrasound can help to confirm the suspected diagnosis of an accessory soleus muscle, without the need to report to biopsy, because it may mimic a soft-tissue tumor. The accessory soleus muscle is known to be asymptomatic in most cases, but pain and swelling can be increased by excessive movement and prolonged standing within the second or third decade of life.

This manuscript based on a bilateral accessory soleus muscle found at the University of Medicine and Health Sciences Anatomy Lab along with information concerning previous accessory soleus muscle discoveries sheds light on how one finds that a human body contains an accessory soleus muscle. In addition, this manuscript helps one grasp what an accessory soleus muscle is, how often this anomaly is seen, as well as, the possible clinical correlations associated with this muscle through data from the previous literature.

\section{References}

1. Kendi T, Erakar A, Oktay O, Yildiz H, Saglik Y. Accessory soleus muscle. J Am Podiatr Med Assoc. 2004;94(6):587-9. https://doi. org/10.7547/0940587

PMid:15547128

2. Carrington S, Stone P, Kruse D. Accessory soleus: A case report of exertional compartment and tarsal tunnel syndrome associated with an accessory soleus muscle. J Foot Ankle Surg. 2016;55(5):1076-8. https://doi.org/10.1053/j.jfas.2015.07.011 PMid:26361954

3. Ekstrom J, Shuman W, Mack L. MR Imaging of accessory soleus muscle. J Comput Assist Tomogr. 1990;14(2):239-42. PMid:2179304

4. Apple J, Martinez S, Khoury M, Nunley J. Case report 376. Skeletal Radiol. 1986;15(5):398-400. https://doi.org/10.1007/ bf00348871

5. Brodie J, Dormans J, Gregg J, Davidson R. Accessory soleus muscle: A report of 4 cases and review of literature. Clin Orthop Relat Res. 1997;337:180-6.

PMid:9137189

6. Önderoğlu S, Erbil K, Tuncel M, Taşcıoğlu B. Accessory soleus muscle. Marmara Med J. 1998;11(4):216-8.

7. Xaviour R, Girijamony VK. Accessory soleus a case report. Int J Sci Res. 2013;2(1):289-91.

8. Rubio F, Franco L, Montero M, Ugarte P, Valero A. Accessory soleus muscle in an athlete. Presentation of a case and a literature review. Apunts Med Esport. 2015;50(186):79-82. https://doi.org/10.1016/j.apunts.2015.01.004

9. Featherstone T. MRI diagnosis of accessory soleus muscle strain. Br J Sports Med. 1995;29(4):277-8. https://doi.org/10.1136/ bjsm.29.4.277 PMid:8808547

10. Peterson D, Stinson W, Carter J. Bilateral accessory soleus A report on four patients with partial fasciectomy. Foot Ankle. 1993;14(5):284-8. https://doi.org/10.1177/107110079301400509 PMid:8349215

11. Yu J, Resnick D. MR imaging of the accessory soleus muscle appearance in six patients and a review of the literature. Skeletal Radiol. 1994;23(7):525-8. https://doi.org/10.1007/bf00223083 PMid:7824980 